\title{
FORMAÇÃO CONTINUADA DE PROFESSORES: A QUESTÃO PSICOSSOCIAL
}

\author{
BERNARDETE A. GATTI \\ Fundação Carlos Chagas \\ gatti@fcc.org.br
}

RESUMO

Mentores e implementadores de programas ou cursos de formação continuada, que visam a mudanças em cognições e práticas, têm a concepção de que, oferecendo conteúdos e trabalhando a racionalidade dos profissionais, produzirão a partir do domínio de novos conhecimentos mudanças em posturas e formas de agir. Essa concepção é muito limitada e não corresponde ao que ocorre nesses processos formativos. Os conhecimentos são incorporados ou não, em função de complexos processos não apenas cognitivos, mas socioafetivo e culturais. Essa é uma das razões pelas quais tantos programas que visam a mudanças cognitivas, de práticas, de posturas, mostram-se inefetivos. Oobjetivo deste trabalho é analisar em que condições podem ocorrer mudanças profissionais e pessoais como resultado de um programa de formação em serviço de professores. Toma-se como caso-referência um programa desenvolvido pelo Ministério da Educação Proformação-, que visa prover a formação de docentes em exercício em regiões menos desenvolvidas do país, docentes estes que lecionam nas escolas de ensino fundamental ( I a a $4^{a}$ séries) sem nenhuma formação para o magistério.

FORMAÇÃO CONTIINUUA-FORMAÇÃO DEPROFESSORES-FORMAÇÃODEPROFESSORES EMEXERCÍCIO-PROFORMAÇÃO

\section{ABSTRACT}

CONTINUED TEACHER TRAINING: A PSYCHOSOCIAL ISSUE. Consultants and those who implement continued training programs or courses that aim to change knowledges and practices have the premise that, by offering content and working on the professional's reasoning process, changes in attitudes and practices will result from mastering of new knowledge. This conception is very limited and does not correspond to what goes on in these training processes. Knowledge is or is not incorporated, according to complex processes that are not just cognitive, but socio-affectivecultural. This is one of the reasons why so many programs that aim to bring about changes in knowledges, in practices, and in attitudes prove to be ineffective. The purpose of this article is to analyze under what conditions professional and personal changes could occur as a result of an inservice training program for teachers. The Proformação program, developed by Ministry of Education, is used as a case for analysis. This program aims to provide training for teachers working in the lesser developed regions of the country, who teach in elementary schools (first to fourth grades) without any formal training in education.

RECURRENTEDUCATION-TEACHEREDUCATION-INSERVETEACHEREDUCATION 
Trabalhos sobre formação em serviço ou continuada e desempenho de professores têm analisado as dificuldades de mudança nas concepções e práticas educacionais desses profissionais em seu cotidiano escolar. Em geral os mentores e implementadores de programas ou cursos de formação continuada, que visam a mudanças em cognições e práticas, têm a concepção de que, oferecendo informações, conteúdos, trabalhando a racionalidade dos profissionais, produzirão a partir do domínio de novos conhecimentos mudanças em posturas e formas de agir. As limitações dessa concepção têm sido tratadas pela pesquisa e literatura em psicologia social, que chamam a atenção para o fato de que esses profissionais são pessoas integradas a grupos sociais de referência nos quais se gestam concepções de educação, de modos de ser, que se constituem em representações e valores que filtram os conhecimentos que lhes chegam. Os conhecimentos adquirem sentido ou não, são aceitos ou não, incorporados ou não, em função de complexos processos não apenas cognitivos, mas, socioafetivo e culturais. Essa é uma das razões pelas quais tantos programas que visam a mudanças cognitivas, de práticas, de posturas, mostram-se ineficazes. Sua centralização apenas nos aspectos cognitivos individuais esbarra nas representações sociais e na cultura de grupos.

Com esta perspectiva, o objetivo deste trabalho é analisar em que condições podem ocorrer mudanças profissionais e pessoais como resultado de um programa de formação em serviço de professores. Tomaremos como caso-referência um programa desenvolvido pelo Ministério da Educação, o Programa de Formação de Professores em Exercício - Proformaç̧ão -, que visa prover, em regiões pouco desenvolvidas do país, a formação de docentes em exercício, os quais lecionam nas escolas de ensino fundamental ( $I^{\mathrm{a}}$ a $4^{\mathrm{a}}$ séries) das redes públicas sem nenhum preparo específico para o magistério.

O programa referido é um curso, em nível médio, que funciona na modalidade de educação a distância, com momentos presenciais coletivos quinzenais e blocos de aulas, também presenciais, de 15 dias a cada semestre. Tem duração de dois anos, com um currículo inovador e utilização de materiais auto-instrucionais, com apoio em textos, livros, vídeos, e conta com um sistema de tutoria que provê o acompanhamento pedagógico sistemático e direto das atividades dos professores-cursistas.

Para nossa análise serão utilizados dados coletados em avaliações externas do Proformação, com a aplicação de questionários, entrevistas e realização de estudos de caso. Trabalharemos com dados constantes dos relatórios feitos pelos responsáveis por essas avaliações, disponibilizados sob forma impressa (Morais, 200 I; 
Placco, André, Gatti, 2002; Placco, 2002; André, 2002, 2002a, Gatti, 2002). Os objetivos deste artigo e o enfoque analítico que adotamos são, porém, bem diversos. Apenas nos apoiaremos nos dados relatados por essas autoras para desenvolver argumentos dentro da perspectiva que nos orienta neste texto.

\section{O PROGRAMA E A COLETA DE DADOS}

O Proformação promove um curso de formação em serviço que se realiza na modalidade a distância, desenvolvendo-se em quatro módulos semestrais, sendo oferecido nas regiões Norte, Nordeste e Centro-oeste do país, onde se concentra alta proporção de professores que trabalham nos anos iniciais do ensino fundamental sem formação suficiente. Para se ter uma idéia, a grande maioria dos professores-cursistas que freqüentaram o programa entre 2000 e 2002 tinha formação apenas até o ensino fundamental, com um grande percentual não tendo concluído sequer esse nível de ensino. O programa desenvolve-se no nível nacional, com apoio de equipes do Ministério da Educação que atuam em parceria com equipes nas secretarias estaduais de educação e com os órgãos municipais de ensino, os quais se responsabilizam pelo trabalho de base, mediante a atuação de tutores e de professores-formadores, das localidades envolvidas. A estrutura curricular do programa é inovadora, compondo-se de um núcleo integrador (eixos integradores e projetos) e de áreas temáticas. $\bigcirc$ material didático e de apoio foi elaborado e testado, visando à sua adequação não só aos objetivos do curso mas também ao tipo de cursista esperado. A avaliação dos professores-cursistas é contínua e se faz por variados meios: cadernos de verificação, compostos de exercícios diversos; memorial, que é um texto que deve ser elaborado pelo cursista quinzenalmente, relatando aspectos de suas experiências no programa, seu aprendizado, suas práticas; observação da prática pedagógica, realizada pelo tutor, abrangendo atividades em sala de aula e planos de aula do professor-cursista; projetos de trabalho, que são projetos educacionais e culturais elaborados e desenvolvidos pelos cursistas; e provas bimestrais.

É importante assinalar que, no início de cada módulo, há um período de 15 dias de trabalho presencial dos professores-cursistas com os professores-formadores. Durante o desenvolvimento de cada módulo, em que os cursistas estudam sozinhos com apoio do material didático fornecido, os professores-cursistas reúnem-se com seu tutor a cada I 5 dias, trabalhando em conjunto um dia inteiro na sede do seu município. Existe ainda o recurso de apoio ao cursista e ao tutor por um plantão telefônico. Como os professores-cursistas lecionam em escolas afastadas das cidades, em pequenas vilas ou sítios, para as atividades presenciais eles se 
deslocam e passam a ter uma convivência diferenciada em relação ao ambiente em que vivem e trabalham cotidianamente. Duas vezes ao mês os cursistas vêm portanto à sede do município, onde desenvolvem as atividades com o tutor. Cada tutor trabalha, em média, com dez professores-cursistas. Na quinzena presencial do semestre eles se hospedam na cidade pólo, onde se situa a escola (chamada Agência Formadora - AGF), que é responsável pela formação de professores-cursistas de um conjunto de municípios próximos. Nessa quinzena têm oportunidade de interagir não só com um novo ambiente, mas com colegas de muitas outras localidades e com profissionais de diferentes formações que atuam no desenvolvimento do currículo. Na cidade pólo têm oportunidade de ampliar seus horizontes culturais. Além disso, em nível local, os tutores visitam regularmente as salas de aula dos professores-cursistas acompanhando sua prática pedagógica.

Os resultados das avaliações externas, realizadas entre os anos 2000 e 2002, dos quais retiramos dados para esta análise, foram colhidos através de:

I. pesquisa de opinião realizada em vários momentos do programa, com questionários aplicados a todos os segmentos envolvidos no processo (membros da coordenação estadual, membros do órgão municipal de ensino, professores-formadores, tutores, professores-cursistas);

2. dados do sistema de monitoramento do programa;

3. observações de fases presenciais e da comunidade;

4. entrevistas com os vários tipos de profissionais envolvidos;

5. estudos de caso;

6. análise dos memoriais dos cursistas.

\section{O CONTEXTO LOCAL}

Antes de passarmos à discussão de alguns dos dados que selecionamos como relevantes para esta análise, queremos mostrar um pouco do cenário no qual nossos personagens constroem-se como pessoas e profissionais. Trazemos para isso trechos de diários de campo de pesquisadores que atuaram nos estudos de caso, em várias localidades. Conforme André (2002, p.67-68), esses relatos colocamnos em sintonia com a ambiência onde o Proformação veio oferecer novas possibilidades aos professores que aí atuam.

A escola está localizada no Km 23 da estrada de Porto Acre, município localizado a 50 minutos de Rio Branco (capital do Estado). Localizada no alto de um pequeno 
morro, a escola, toda de madeira muito desgastada e comida pelos cupins, possui duas salas amplas e com muitas janelas e uma cozinha só com uma pia. As poucas panelas, pratos e talheres ficam guardados no chão. Não há armário e a água que as crianças bebem é do poço da casa da merendeira. Da mesma forma, o banheiro também é precário, fica fora da escola mas se apresentava bem limpo. (Diário de Campo AGF de Rio Branco, Estado do Acre)

A escola é composta por 2 salas, uma para a la série (e pré-escola) e a outra para a $2^{a}$ série; um banheiro e uma cantina. Não tem telefone, mas podem recorrer ao telefone público, um orelhão em frente ao portão. Não há pátio e, sim, um quintal de terra com pouca vegetação. A sala de aula não tem janelas, mas buraquinhos quadrados de 10 por $10 \mathrm{~cm}$ que permitem a entrada de luz. A cantina é simples: um fogão, aliás, são duas bocas com botijão; uma cisterna para armazenar a água, que atualmente chega somente de 8 em 8 dias; uma geladeira, com poucas garrafas de refrigerantes cheias de água. (Diário de Campo, AGF de Quixadá, Estado do Ceará) Esta escola fica numa fazenda de cacau na localidade chamada "Beira do Rio", a mais longínqua da sede do município. São quase 20 km de estrada de terra, precária, do tipo "se chove não entra, se chove não sai". Não há energia elétrica nesta região. A distância, a falta de transporte e a ausência de energia elétrica significam um enorme isolamento para esta comunidade. É difícil sair da Beira do Rio, não há acesso a noticiários e não há circulação de materiais escritos. A escrita está presente quase que unicamente em situações escolares. (Diário de Campo AGF de Gandu, Estado da Bahia)

Os relatos fornecem uma viva idéia do contexto das regiões em que os professores-cursistas, que freqüentaram o Proformação, trabalham e vivem. À pobreza material somam-se as parcas condições de contatos com o mundo exterior, as quase ausentes possibilidades desses professores de ampliar sua formação educacional e profissional. Tais condições ressaltam as características básicas da textura social na qual o programa adentrou, visando propiciar a esses professores, com base no modelo adotado, condições de estudo e de diversificação de contatos culturais e sociais.

\section{OS RESULTADOS E UMA PERGUNTA}

programa mostra resultados que refletem sua efetividade, mesmo com alguns problemas intercorrentes e a heterogeneidade nos desempenhos.

Os dados do sistema de monitoramento do Proformação (Gatti, 2002) mostram que quase $90 \%$ dos professores-cursistas que acompanharam todo o programa conseguiram ser aprovados nas avaliações e obtiveram certificado. Tanto as 
observações feitas nas visitas às escolas dos professores cursistas, quanto os resultados dos testes de simulação didática aplicados, assim como a análise dos memoriais, atestam mudanças positivas na prática pedagógica dos professores-cursistas, em vários aspectos, como por exemplo, no planejamento e na preparação das atividades docentes, na organização do espaço da sala de aula e no uso de material concreto e outros recursos, na interação professor-aluno, na articulação do conteúdo com as experiências culturais dos seus alunos. Isto também ficou evidenciado nas respostas à pesquisa de opinião (Placco, André, Gatti, 2002, p.26).

Os dados obtidos pelas avaliações externas do Proformação mostram, portanto, que o programa produziu mudanças significativas na vida profissional e pessoal desses professores, como trouxe a possibilidade de aprendizagens de novos conteúdos nas diferentes áreas temáticas abordadas pelo currículo.

A questão que formulamos diante dos resultados é: que condições permitiriam a produção desses impactos e transformações no modo de pensar e nas práticas?

\section{PROFESSORES/AS: SERES PSICOSSOCIAIS}

Para responder à questão, consideramos alguns aspectos básicos que a literatura em psicologia social vem consolidando (Dubar, 2000; Scheibe, 1995; László, Rogers, 2002; Guareschi, Jovchelovitch, 1995). É preciso ver os professores não como seres abstratos, ou essencialmente intelectuais, mas, como seres essencialmente sociais, com suas identidades pessoais e profissionais, imersos numa vida grupal na qual partilham uma cultura, derivando seus conhecimentos, valores e atitudes dessas relações, com base nas representações constituídas nesse processo que é, ao mesmo tempo, social e intersubjetivo. Há também que se considerar o papel de eventos mais amplos, sejam sociais, políticos, econômicos ou culturais, com seus determinantes que perpassam a vida grupal ou comunitária. Sabemos que a interação desses fatores molda as concepções sobre educação, ensino, papel profissional, e as práticas a elas ligadas, concepções e práticas estas que, por sua vez, são estruturalmente delimitadas pela maneira que as pessoas se vêem, como estruturam suas representações, como se descrevem, como vêem os outros e a sociedade à qual pertencem.

Daí decorre ser muito simplista a noção de que o aumento e a melhoria do rol de conhecimentos informativos, adquiridos individualmente, será suficiente para melhorar ou modificar conceitos e práticas ligados ao trabalho profissional de professores. Essa concepção não dá conta da complexa dinâmica sociopsicológica en- 
volvida nas relações entre conhecimento, valores, atitudes e ações. A cultura, os significados partilhados e o meio social permeiam as experiências individuais, construindo as referências com as quais ou em contraposição às quais as pessoas agem. O conhecimento é enraizado na vida social, expressando e estruturando a identidade e as condições sociais dos que dele partilham. Por isso, ações sociais ou educacionais que têm por objetivo criar condições de mudanças conceituais, de atitudes e práticas precisam estar engrenadas com o meio sociocultural no qual as pessoas, os profissionais, que serão abrangidos por essas ações, vivem. Metaforicamente, diríamos que a alavanca tem que se integrar ao terreno para mover o que pretende mover.

Programas formativos, intervenções que visam trazer impactos e diferenciais nos modos de agir de pessoas/profissionais só mostram efetividade quando levam em consideração as condições sociopsicológicas e culturais de existência das pessoas em seus nichos de habitação e convivência, e não apenas suas condições cognitivas. Mas apenas o levar em consideração essas questões como premissas abstratas não cria mobilização para mudanças efetivas. O que é preciso conseguir é uma integração na ambiência de vida e trabalho daqueles que participarão do processo formativo.

Nossa análise dos dados obtidos nos relatórios citados será guiada por essa perspectiva, pela qual buscamos quais elos criaram condições para as mudanças detectadas.

Formas e processos de representação estão involucrados nos processos de transcrição do mundo e de si, e as narrativas que expõem esses processos são manifestações da atividade simbólica das pessoas as quais fornecem elementos para detecção e compreensão desses processos, que podem traduzir cristalizações, resistências ou transformações, metamorfoses na expressão de Ciampa ( 200 I). As narrativas serão nosso ponto de apoio.

\section{ELOS CRIADOS: AMBIÊNCIA PARA O DESENVOLVIMENTO E A MUDANÇA}

Das observações que fizemos no início deste trabalho, decorre o argumento de que se esse programa formativo para professores fosse apenas um curso implementado com uma racionalidade que passasse ao largo das condições de vida, da linguagem, dos tipos de trocas, valores, das formas de representar o mundo dessas pessoas a quem ele se destina, o mais provável seria, conforme a literatura em psicologia social tem mostrado (Farr, 1996), que ele não conseguisse deixar com esses profissionais novos marcos referenciais para suas vidas e seu trabalho. 
No caso do Proformação, o que se observa como resultante, pelos dados relatados, é que importantes mudanças aconteceram, a partir das oportunidades interativas oferecidas, como exemplificado em Morais (200 I) nas falas a seguir:

....antes do Proformação deixava o aluno de lado (o que não aprendia)...agora me dedico mais a ele que aos outros... pergunto o que gosta de fazer, converso mais... tudo isso tem dado certo... (Cursista, Município de Itamari, Bahia, p.29)

...depois do Programa estou me achando uma pessoa mais solta, uma pessoa que, sei lá, me soltei mais... sei conversar melhor... foi isso. (Cursista, Município de Ipecaetá, Bahia. p.2I)

Ou nos relatos citados por André (2002), em análise dos memoriais dos cursistas:

É muito gratificante saber que já estou finalizando a terceira etapa do curso Proformação. Sem dúvida foi muito positivo, tive muitos avanços durante este percurso. Foram muitos os momentos de alegria, mas também de aperto e angústia. Para mim os encontros dos sábados sempre foram de satisfação, encontrar-me com os colegas professores-cursistas e tutores e esperar ver em cada um sempre um sorriso de vitória. (Cursista, Quixadá, Ceará, p.6)

Eu tinha uma visão atrasada a respeito das dificuldades de aprendizagem de alguns alunos (...). Posso deixar o preconceito de lado e parar de achar que certas crianças têm dificuldades de aprendizagem por causa da vida difícil que levam. (Cursista, Gandu, Bahia, p.63)

Agora estou sempre com um livro na mão. Meu marido é que não entende porque estou tão interessada em estudar, mas eu gosto muito. Adquiri o hábito de ler e pesquisar. (Cursista, Cruzeiro do Sul, Acre, p.33)

O meu crescimento pessoal tem sido surpreendente, pois aprendi a me relacionar com minha família, entendendo melhor minhas crianças, ...compreendi suas diversas formas de brincar, bem como seu comportamento e suas ações. (Cursista, Cruzeiro do Sul, Acre, p.32)

O Proformação tem me transformado muito e estou muito feliz com essas mudanças, pois estou desenvolvendo melhor o meu trabalho e até me relacionando meIhor com as pessoas. (Cursista, Cruzeiro do Sul, Acre, p.32)

Várias mudanças em concepções e práticas pedagógicas, também mudanças pessoais, são sinalizadas nos relatórios citados, com dados corroborantes, seja dos opinionários, das entrevistas ou das observações. Atribuímos essas mudanças e as incorporações de novas idéias e modos de ser ao entrelaçamento do programa 
com o meio no qual as pessoas a que ele se destina vivem. Esse entrelaçamento foi propiciado, por exemplo, por estudos sobre as condições da compreensão dos materiais, antes e durante as primeiras experiências de implementação do programa, sofrendo mudanças antes de outras implementações.

A cada dia me surpreendo com os textos do Guia do Proformação, pois eles estão de acordo com a nossa realidade e isso facilita muito o trabalho pedagógico. (Cursista, Gandu, Estado da Bahia; cf. André, 2002, p.59)

...os guias são ótimos, eu acho, assim, que eles têm uma linguagem tão clara que parecem que estão conversando; é como se tivesse conversando com o professor na sala ... eu mesma acho isso, que ele conversa comigo. (Cursista, Município de Nova Fátima, Bahia; cf. Morais, 200 I, p. 12)

Também houve ajustes contínuos na gestão e forma de desenvolvimento nas localidades, com negociações diversas entre as diferentes esferas participantes: os técnicos do nível federal, do estadual e do municipal. O envolvimento das administrações educacionais locais e seus profissionais na realização direta do programa permitiu a construção de elos fortes entre programa, realizadores e participantes, criando os vínculos socioculturais para que essa intervenção pudesse ter algum sucesso. Esses vínculos foram possíveis pelo envolvimento do órgão municipal de educação não só por dar suporte direto para deslocamentos dos professores cursistas, seu alojamento na cidade, garantindo os locais para os encontros, o que sinaliza o compromisso das administrações locais, sobretudo, pelo atendimento continuado oferecido pelos tutores aos professores-cursistas, tutores estes que são pessoas do próprio local em que o curso se desenvolve, portanto participantes da mesma cultura regional.

Para que esse programa tivesse êxito foi imprescindível sua implementação com a utilização de materiais impressos e videográficos de alta qualidade, como também a participação efetiva dos professores-cursistas nas atividades presenciais, o compromisso dos tutores e o acompanhamento dos professores-formadores durante todo o curso. (Coordenadora de AGF, região de Feira de Santana, Bahia; cf.André, 2002a, p. 18)

A pequena evasão de $10 \%$ constatada no programa, quando em geral nos projetos de educação a distância índices bem superiores são verificados, entre 40\%, e 50\%, é um sinal de que se formaram vínculos fortes o suficiente para que os professores-cursistas não desistissem do curso. Isso, a despeito das suas dificuldades para estudar em boa parte do tempo sozinhos, uma vez que a grande maioria tinha pre- 
cária formação, com boa porcentagem sem ter mesmo o ensino fundamental completo. Acresça-se o fato de esses cursistas, em sua maioria, terem deixado o ensino regular há mais de 15 anos. O que se observou foi que a falta de hábitos de leitura e estudo, suas dificuldades de compreensão de textos e de escrever, foram sendo superadas no contexto de uma ambiência de apoio criada pela tutoria, com valores, linguagem, modos de ser socialmente próximos aos dos cursistas, pela interação com o grupo de colegas nos encontros quinzenais, pela motivação dos encontros semestrais mais amplos, com outros professores-cursistas e professores-formadores, pelos vários eventos programados etc. Os agentes educacionais no Proformação, por sua experiência de vida próxima à dos cursistas e mesmo pela formação a eles oferecida pela gestão do programa, reconhecendo significados, representações, valores das comunidades de referência dos professores-cursistas, puderam desenvolver relações e estratégias de ensino para buscar, durante esse processo, as melhores formas para atingir os objetivos do Proformação. As falas mencionadas no estudo de Morais (200 I) mostram esse aspecto:

Quando a gente sente alguma dificuldade tem a quem procurar e antes a gente não tinha...a visita (da tutora) é o momento em que ela fica com a gente, vê todo o andamento da aula, orienta em alguma coisa e acho que isso é muito importante. (Cursista, Município de Rafael Jambeiro, Bahia, p. I4)

...eu nunca fiquei de recuperação...tenho passado direto e eu acho que isso tem a ver com a própria metodologia do curso porque nós temos os tutores que nos ajudam a cada I 5 dias, os livros que nos ajudam muito e o próprio curso fala a nossa linguagem. (Cursista, Município de Guajumirim, Rondônia, p. 13)

Ainda, nesta ótica, um fator fortemente vinculante, parece-nos ser a integração das práticas dos próprios professores-cursistas em suas salas de aula como eixo para o desenvolvimento curricular do programa.

.... Proformação... veio atender o professor em tudo porque os outros cursos não contavam com nossa prática em sala de aula e o Proformação conta, e é muito bom por isso...e é um curso moderno, a gente vê nos cadernos, nos conteúdos que é coisa atual... (Cursista, Município de Guajumirim, Rondônia, p.9)

Conforme Gervais e Jovchelovitch ( 1998 ) escrevem, crenças e práticas são construídas num contexto de interação e negociação social constantes, em que o compromisso com a identidade social, normas grupais e tradições culturais têm um papel central. Conceitos e práticas são recheados pelas interações entre idéias e 
representações que constituem referência numa sociedade e representações e idéias que os indivíduos criam para si mesmos em decorrência de suas relações próximas em comunidades. Assim, formas interativas que propiciam convivências e interações com novos conteúdos culturais, com pessoas de outros ambientes e com idéias e níveis de informação diversificados, constituídas com o objetivo de entrosar elementos do contexto existente com novas experiências, parecem ser o caminho mais propício à criação de condições de integração de novos conhecimentos de modo significativo e de mudança ou criação de novas práticas.

Nesse programa, quando se considera os aspectos interacionais vinculantes, a figura do tutor é realmente uma figura-chave no processo de criar os laços sociocognitivos, afetivos e motivacionais, entre o programa e sua proposta e os professores-cursistas. $\bigcirc$ tutor constituiu-se em elo privilegiado de comunicação entre os professores-cursistas e o material didático, os projetos de trabalho e os professoresformadores. Pertencente à comunidade próxima, sua presença nas escolas dos professores-cursistas, a forma participativa de seu trabalho quinzenal com eles sobre as tarefas do período, suas avaliações continuadas, a busca de apoio dos professoresformadores para sustentar seu trabalho junto aos cursistas, possibilitou a formação de uma rede de informação e comunicação, de relações e trocas produtivas, de laços culturais efetivos. Em André (2002a) encontramos depoimentos escritos nos memoriais que ilustram isso, como, por exemplo, o de uma professora-cursista da região de Feira de Santana (Bahia) que diz "o relacionamento com as pessoas com as quais convivi durante este tempo do curso foi ótimo, mudei minha prática pedagógica com as orientações da minha tutora, os professores-formadores, que nos orientaram muito." Também em Morais (200 I ) temos boas evidências, nas falas dos cursistas que entrevistou, sobre o papel do tutor como elo psicossocial e cultural:

...as tutoras trabalham com garra, organizam tudo, cumprem seu papel direitinho, preparam o material, estão sempre bem-humoradas e não desanimam... (Cursista, Piraí do Norte, Bahia, p. 14)

... a gente aprendeu coisas novas, metodologias novas, visitas dos tutores, né? (Cursista, Rafael Jambeiro, Bahia, p. 14)

Morais (200 I , p.82-84), para seu estudo do Proformação, entrevistou ainda os próprios tutores, e se pode verificar nos relatos deles seu papel central na formação dos elos de comunicação e aprendizagem. Ao analisarmos as falas transcritas, esse papel aparece na forma como eles se relacionam com os professores-cursistas, na consideração pela experiência desses cursistas e seu reconhecimento, na consciên- 
cia de seu próprio papel social, na determinação em fazer dar certo, na compreensão da situação socioeducacional dos professores-cursistas pela proximidade na comunidade, até no reconhecimento explícito de sua função de elemento de ligação:

.... gente tem que ter simplicidade com eles... vou estar investindo neles, porque vale a pena ser investido...e eles são compreensíveis... eu nunca imaginei que pessoas de certa idade tinham tanto para me ensinar (os professores-cursistas) ...e eles são carentes de um estudo, carentes de ter entrado em uma escola, e eles têm muito o que ensinar para nós... (Tutora, Cruzeiro do Sul, Acre)

...sei que o que faço ajudará não só o professor-cursista, mas também terá um grande retorno profissional para mim e para a área educacional. (Tutora, Campo Novo, Roraima)

Tenho garra e pulso para esse pique, tenho energia e quero gastá-las com algo que vai ter retorno... (Tutora, Buritis, Rondônia)

.... g gente conhece a realidade deles e aí o que é que a gente faz, a gente trabalha até mesmo fora do Proformação... (Tutora, Ipecaetá, Bahia)

.... tutoria serve até de elo entre eles e a Secretaria de Educação, porque as comunidades são distantes. (Tutora, Candeal, Bahia)

\section{CONCLUINDO}

Os muitos dados apresentados nos relatórios referidos deixam claro que o Proformação atingiu em boa parte seus objetivos. Embora uma pequena proporção dos professores-cursistas não tenha concluído o curso, ainda que se verifiquem algumas dificuldades com a linguagem e o conteúdo dos guias curriculares e, também, alguns desajustes de gestão em certos locais e momentos da implementação desse programa - o que parece marcante no desenvolvimento de ações de grande porte como esta, que já atingiu quase 40 mil professores -, verificou-se que a maioria dos professores-cursistas não só concluiu o curso, como este se entrelaçou com suas vidas e experiências profissionais. Desse entrelaçamento deriva-se a efetividade e a possibilidade de um impacto que perdure no futuro desses profissionais. Os relatos, extraídos do texto de André (2002a), ilustram esse caminho.

Como profissional seria hipócrita se dissesse que não cresci, pois passei a entender melhor o meu aluno, respeitando a individualidade de cada um, adquiri o hábito de ler mais, e obtive bons rendimentos na minha prática pedagógica com aulas mais dinâmicas. Aprendi a expor minhas idéias, enfim, foram vários conhecimentos obtidos. Tudo isso leva-me a ter certeza que o curso tem sido de grande influência 
nessas mudanças e conhecimentos obtidos, creio que ao final do mesmo sairei não só com um diploma, mas sim, como uma profissional qualificada convicta do que irei fazer. (Cursista, Cruzeiro do Sul, Acre, p.20)

Hoje vejo que professor tem que trabalhar porque é um profissional. E que ele tem que se capacitar para melhor ensinar, para ter um salário maior, para ser visto e reconhecido pelo seu talento e capacidade. Professor tem que ser livre para falar de liberdade para seus educandos. E o Proformação tem alargado esta visão, fazendo com que me sinta importante e capaz, é só querer. (Cursista, Quixadá, Ceará, p. 19) ...antes, eu não tinha o pensamento de enfrentar uma faculdade. Nestes dois anos, eu me acostumei a estudar e é isso que me dá força para continuar... (Cursista, Quixadá, Ceará, p.28)

Retomando nossas premissas, a particular leitura que fizemos dos dados apresentados em outro contexto e com outros objetivos pelas autoras citadas, reforça os aspectos levantados por vários estudos em psicologia social (Lane, Sawaya, 1994; Sawaya, 1987). A consideração de que elementos relacionais, socioculturais contribuem de modo interativo para a constituição e reificação do arcabouço da representação - que como tal, é fator interveniente na própria dinâmica relacional em que se gera - permite-nos afirmar que as intervenções socioeducacionais, que incidem necessariamente sobre um modo psicossocial específico de valorar fatos ou conhecimentos, de interpretar, atribuir sentido podem ser mais significantes se levarem em conta essas questões e os elementos de entrelace necessários. $\bigcirc$ que observamos é que o Proformação, em vários aspectos, levou em consideração tais questões, dada a maneira pela qual foi implementado, embora elas não estivessem explicitadas em seu modelo. Ao conseguir um entrelaçamento com a cultura, com os modos de ser e valores das comunidades regionais e, com base nisso, ao propor novos conteúdos curriculares e práticas pedagógicas - objetivos desse curso de formação de professores -, produziu condições facilitadoras de apreensão de novas idéias e criação de outras formas de agir pedagógica e socialmente. $\bigcirc$ impacto obtido, nos contextos em que se realizou e com o particular tipo de professorescursistas aos quais se destinou, mostra a importância da consideração dos aspectos culturais, psicossociais, no desenvolvimento de aprendizagens e na apreensão de novos valores, o que se vincula a mudanças de práticas.

Tudo isso reforça a idéia de que, para que mudanças em concepções e práticas educacionais de professores ocorram, é necessário que os programas que visam a inovações educacionais, aperfeiçoamentos, atualizações tenham um entrelaçamento concreto com a ambiência psicossocial em que esses profissionais trabalham e vivem. 


\section{REFERÊNCIAS BIBLIOGRÁFICAS}

ARRUDA, A. (org.). Representando a alteridade. Petrópolis: Vozes, 1998.

ANDRÉ, M. E. D. A. Proformação: relatório de análise dos memoriais. São Paulo: PUC/ MEC/SEED, 2002.

SEED, 2002a.

Proformação: relatório final dos estudos de caso. São Paulo: PUC/MEC/

CIAMPA, A. da C. A Estória do Severino e a história da Severina: um ensaio de psicologia social. 7. reimpr. São Paulo: Brasiliense, 2001 .

DUBAR, C. La Crise des identités. l'interpretation d'une mutation. Paris: PUF, 2000.

FARR, R. The Roots of modern social psychology. Oxford: Blackwell, 1996.

GATTI, B. A. Proformação: relatório final dos dados do sistema de monitoramento. São Paulo: PUC/FCC/MEC/SEED, 2002.

GERVAIS, M. C.; JOVCHELOVITCH, S. The Health beliefs of the chinese community in England. a qualitative research study. London: Health Education Authority, 1998.

GUARESCHI, P.; JOVCHELOVITCH, S. (orgs.). Textos em representações sociais. 2. ed. Petrópolis: Vozes, 1995.

LANE, S. T. M.; SAWAYA, B.B. (orgs.) Novas veredas da psicologia social. São Paulo: Brasiliense; Educ, 1994.

LÁSZLÓ, J.; ROGERS, W. S. (eds.) Narrative approches in social psychology, Budapest, Hungary: New Mandate, 2002.

MORAIS, T. C. Avaliação externa: entrevistas, Proformação. Brasília: MEC/SEED, 200 I.

PLACCO, V. M. N. S. Proformação: relatório final da pesquisa de opinião. São Paulo: PUC/ MEC/SEED, 2002.

PLACCO, V. M. N. S.; ANDRÉ, M. E. D .A.; GATTI, B. A. Proformação: relatório final geral da avaliação externa do programa. São Paulo: PUC/FCC/MEC/SEED, 2002.

SAWAYA, B. B. A Consciência em construção no trabalho de construção da existência. 1987. Tese (Doutorado) PUC, São Paulo.

SCHEIBE, K. E. Self studies. the psychology of self and identity. Westport, London: Praegger, 1995.

Recebido em: março 2003

Aprovado para publicação em: março 2003 